\title{
Development of a multidisciplinary method to determine risk factors for arm fracture in falls from playground equipment
}

\author{
S Sherker, J Ozanne-Smith, G Rechnitzer, R Grzebieta
}

Injury Prevention 2003;9:279-283

See end of article for authors' affiliations

Correspondence to: Shauna Sherker, Monash University Accident Research Centre, PO Box 70A, Monash University, VIC 3800, Australia; shauna.sherker@ general.monash.edu.au thod to investigate physical risk

Objectives: To present the development of a
factors for playground related arm fracture.

Rationale: Previous playground injury research has been limited in its ability to determine risk factors for arm fractures, despite their common and costly occurrence. Biomechanical studies have focused exclusively on head injury. Few epidemiological studies have quantified surface impact attenuation and none have investigated specific injury outcomes such as arm fracture.

Design: An unmatched case-control study design was developed. An instrumented child dummy and rig were designed to simulate real playground falls in situ. Validated output from the dummy was used to quantify arm load. Other field measurements included equipment height, fall height, surface depth, headform deceleration, and head injury criterion.

Discussion: Validated methods of biomechanics and epidemiology were combined in a robust design. The principle strength of this method was the use of a multidisciplinary approach to identify and quantify risk and protective factors for arm fracture in falls from playground equipment. Application of this method will enable countermeasures for prevention of playground related arm fracture to be developed.
$\mathrm{P}$ layground related injury is a serious and common event in childhood, accounting for substantial morbidity and cost. In Victoria Australia, over 5000 children present to hospital emergency departments each year and $22 \%$ are hospitalised with playground related injuries. ${ }^{1}$ This represents approximately $6 \%$ of all hospital treated child injuries ${ }^{1}$ and medical treatment costs of AUD\$7.9 million per year in Victoria $(1996 / 97){ }^{2}$

Playground injury most often results from falls from equipment, with arm fracture accounting for $43 \%$ of emergency department presentations and $74 \%$ of hospital admissions. ${ }^{1}$ Most injury occurs to children aged less than 13 years, chiefly in school playgrounds. ${ }^{1}$

Risk factors include equipment height and the type of surfacing onto which children fall. ${ }^{3-7}$ There is no consensus on the most effective maximum height of playground equipment to minimise risk of injury. Recommendations range from $1.5 \mathrm{~m}^{4}$ to $4.0 \mathrm{~m}^{8}{ }^{8}$ There is also debate on the most effective surface. ${ }^{910}$

Limitations in previous analytical studies include: not quantifying the impact attenuation of surfacing ${ }^{3-5} 7$; measurement bias in using height of equipment as a proxy for fall height $^{4-7}$; and limited statistical power for specific injury outcomes, especially arm fracture..$^{3-6}$

The head injury criterion (HIC) is a measure of the probability of skull fracture in adults and correlates with the magnitude of deceleration and duration of impact. ${ }^{11}$ As the HIC was developed from adult cadaver tests, generalisation to the probability of injury in children has been questioned. ${ }^{12}$ Laboratory based measures of HIC are nonetheless used to define surface and height requirements for playground safety, where peak deceleration below $200 \mathrm{~g}$ and HIC values below 1000 are recommended. ${ }^{813}{ }^{14}$ Current playground impact tests have limited generalisability due to their specificity for head injury risk.

To date, no studies have addressed the specific risk factors for arm fracture. Public health research in playground injury has almost exclusively used epidemiological methods. Few studies have integrated biomechanical and epidemiological methods in injury prevention research, a combination recommended to bridge the gap between problem identification and technological solution. ${ }^{15}$

Our aim was to combine the best methods of epidemiology and biomechanics to investigate and quantify fall height and surface impact characteristics as risk factors for arm fracture in children falling from playground equipment.

\section{METHODS AND RESULTS \\ Design}

An unmatched case-control study (fig l) was the most appropriate design in terms of specificity, effect size, potential bias, cost, and timeframe. ${ }^{16}$ Upon review of epidemiological data, ${ }^{1}$ the study base was children aged less than 13 years who fell from playground equipment located in primary schools and preschools and landed on their arm.

Cases were defined as children under 13 who sustained an upper limb fracture as a result of falling from playground equipment at a school or preschool. Fractured long bones of the upper extremity (humerus, radius, and ulna) represented the largest and most costly group of playground related injury. ${ }^{2}$ Cases included diagnoses corresponding to ICD10-AM codes S42.2, S42.3, S42.4 (fracture of humerus), S52 (fracture of forearm, including radius and/or ulna), and T10 (fracture of upper limb, level unspecified). ${ }^{17}$

Controls were children of the same age, in the same settings, who also fell from playground equipment and landed on their arm but did not suffer an arm fracture.

Sample size estimates were based on the following assumptions: alpha error $=0.05$; beta error $=0.20(80 \%$ power $)$; and

Abbreviations: CoG, centre of gravity; HIC, head injury criterion 


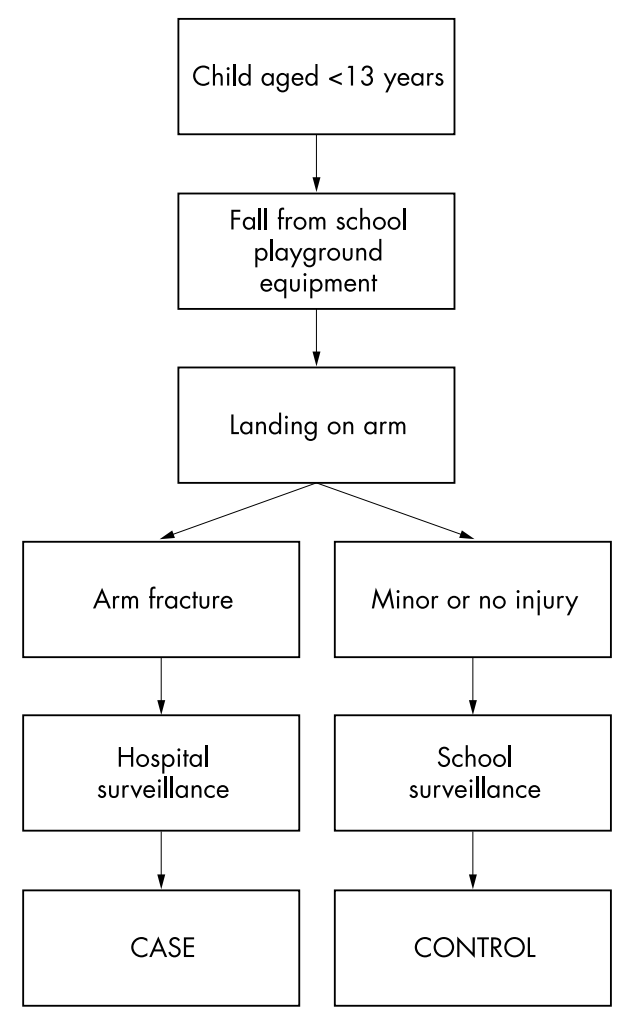

Figure 1 Case-control study design.

a "clinically important" odds ratio of $2.0 .^{18}$ A random sample of 176 pieces of playground equipment were audited to determine compliance with the currently recommended safety guidelines and to estimate children's exposure to the risk factors of interest (equipment height and surface characteristics). Prevalence of non-compliant playgrounds was $90 \%$. Sample size estimates specified that 533 cases and 533 controls were required. ${ }^{19}$

Five hospitals were selected for case recruitment, representing $38 \%$ of all playground related injury admissions in Victoria. ${ }^{1}$ Ethics committee approval was obtained to access patient medical records. Hospital emergency department staff checked patient records weekly to identify children meeting the eligibility criteria. Children with non-confirmed fractures of the long bones of the upper extremity were excluded.

Control schools were recruited randomly from the catchment area of participating hospitals. Feasibility of control ascertainment was estimated from the annual number of non-fracture injuries from Department of Education data sources. Based on a reported recruitment rate for controls of $89 \%$ in a similar study, ${ }^{4} 34$ schools were required. Staff at control schools were trained to record playground falls using a standard confidential incident report form.

An ascertainment protocol was designed to recruit cases and controls. Upon notification of cases and controls and written parental consent, an interview with the child was arranged as soon as possible after their fall. National ethical guidelines were followed. ${ }^{20}$

\section{Interview protocol}

An interview protocol was developed to determine from which equipment the child fell, the fall height, and the location where their arm impacted the playground surface. Case and control interviews used identical protocols.

Children were interviewed at the fall site in the playground and reported their own fall details. This improves on previous study designs where parents or other proxies completed a questionnaire regarding the child's fall, often using a photograph to identify fall location. ${ }^{36}$
Table 1 Variables measured for each fall event

\begin{tabular}{|c|c|c|}
\hline Child variables & $\begin{array}{l}\text { Playground } \\
\text { variables }\end{array}$ & Fall variables \\
\hline $\begin{array}{l}\text { Age } \\
\text { Gender }\end{array}$ & $\begin{array}{l}\text { Equipment type } \\
\text { Equipment height }\end{array}$ & $\begin{array}{l}\text { Position at start of fall } \\
\text { Fall height (based on child } \\
\text { CoG) }\end{array}$ \\
\hline $\begin{array}{l}\text { Height } \\
\text { Weight } \\
\text { Body mass index } \\
\text { Handedness }\end{array}$ & $\begin{array}{l}\text { Surface type } \\
\text { Surface depth } \\
\text { Surface moisture } \\
\text { Surface age }\end{array}$ & $\begin{array}{l}\text { Peak deceleration }(g) \\
\text { Head injury criteria } \\
\text { Arm load }(k N)\end{array}$ \\
\hline
\end{tabular}

Children were asked: From which piece of equipment did you fall?; What were you doing just before you fell?; and Where did you land?. Height and clothed weight of the child were measured and handedness recorded.

Interview questions were designed for their simplicity and specificity. To ascertain the validity of child self report, child interview responses were compared to those of an adult witness and to details from school injury reports, where available. Preliminary results indicate good child recall and no differential recall bias between cases and controls.

\section{Field test protocols}

Playground safety standards $s^{813}{ }^{14}$ were reviewed to develop field test protocols with the objective of measuring the physical characteristics of the playground equipment and surface where the child fell.

Field measurements are shown in table 1. Depth of surface material was calculated as the average of three probe readings taken $30 \mathrm{~cm}$ apart in a triangle around the point of contact. ${ }^{14}$ To better describe surface characteristics, moisture content (dry, residual moisture, wet), age (weeks since installation), and surface substrate were also recorded.

Equipment height was defined as the vertical distance from the surface to the highest accessible part of the structure. ${ }^{21}$ Child fall height was the vertical distance between the playground surface and the child's centre of gravity (CoG) at the start of their fall. CoG tables were derived based on child anthropometric data, ${ }^{22}$ adapted for the various positions commonly reported at the start of children's falls (for example, standing, hanging from arms).

Inter-rater reliability of field test measurements between two testers averaged 0.9904 in a random sample of 46 playgrounds.

\section{Development of instrumentation \\ Headform}

A $5.4 \mathrm{~kg}$ child headform instrumented with a triaxial accelerometer (Playground Clearing House MAX G/SI) was used to determine critical deceleration and HIC as standard measures of playground safety. ${ }^{14}$ Drop tests in the field were conducted from three heights: $1 \mathrm{~m}$, child fall height, and maximum equipment height.

\section{Novel impact arm load dummy}

The headform impact tests were limited by their specificity to the risk of head injury. Review of playground injury epidemiology indicated that impact arm loads should be quantified in order to specifically investigate the risk factors for arm fracture.

An exhaustive search of existing anthropometric models did not identify an appropriate dummy to investigate the risk of child arm fracture. Thus, an anthropometric dummy capable of measuring impact arm loads was built according to height and weight data for the proposed sample (fig 2).

The size and shape of the dummy was based on a surrogate 6 year old. ${ }^{24}$ The dummy was constructed of $6 \mathrm{~mm}$ steel with 

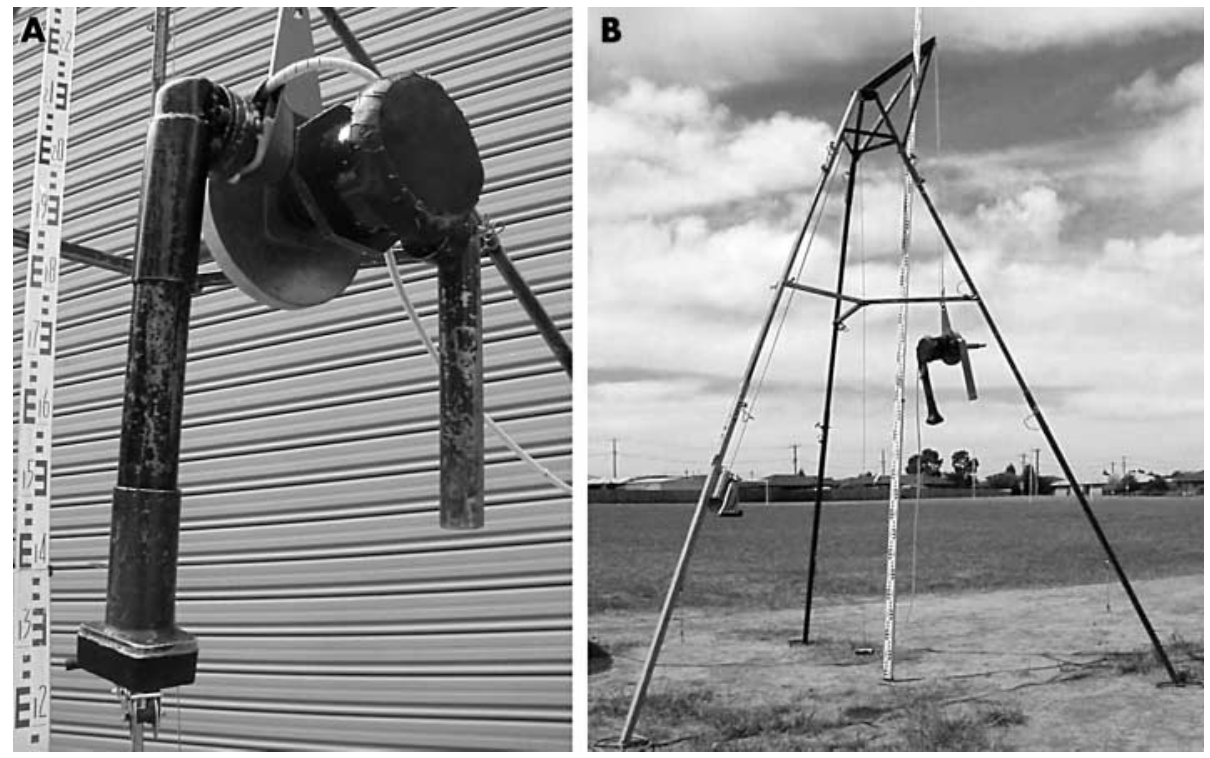

Figure 2 Instrumented anthropometric child falls dummy (left) and drop rig (right) shoulder breadth $285 \mathrm{~mm}$, arm length $420 \mathrm{~mm}$, and the palm $75 \times 65 \mathrm{~mm}$. The dummy alone weighed $10 \mathrm{~kg}$ and purpose built durable plate weights were added to simulate the mass of a child up to $50 \mathrm{~kg}$ (95th percentile for children $<13$ years).

The dummy was instrumented with a full bridge foil strain gauge forming a load cell to measure $0.5 \mathrm{kN}$ to $25 \mathrm{kN}$ axial loads. The required range and sensitivity of the load cell were determined by pilot testing on various surface materials in the laboratory. The sensor was placed in the forearm of the dummy, just above the hand plate, and calibrated at regular intervals. The dummy arm without the sensor was shorter than that with the sensor to ensure the capture and estimation of the full axial load on the child's arm in the fall. To simulate the child's fall, drop tests in the field were conducted from the child's actual fall height.

A manual trigger was depressed to initiate data sampling. The analogue output from the load cell was sampled at 20000 $\mathrm{Hz}$ using a 16 bit analogue-to-digital converter. The digital signal was amplified (100:1) and interfaced with a laptop PC running custom written data acquisition software (HP VEE version 5.01).

A rugged laptop PC (GETAC A-7407) was selected for its durability and all-weather field testing capability. A computer data acquisition card (DT300) with a $+5 \mathrm{~V}$ dc 1 Amp supply line was used to power the load cell. The data acquisition system was fully battery operated by one tester in the field.

\section{Drop test rig}

A portable drop test rig was designed to lift each drop device to the child's fall height and release it into free fall to the surface (fig 2). This provided reliable, repeatable measurements

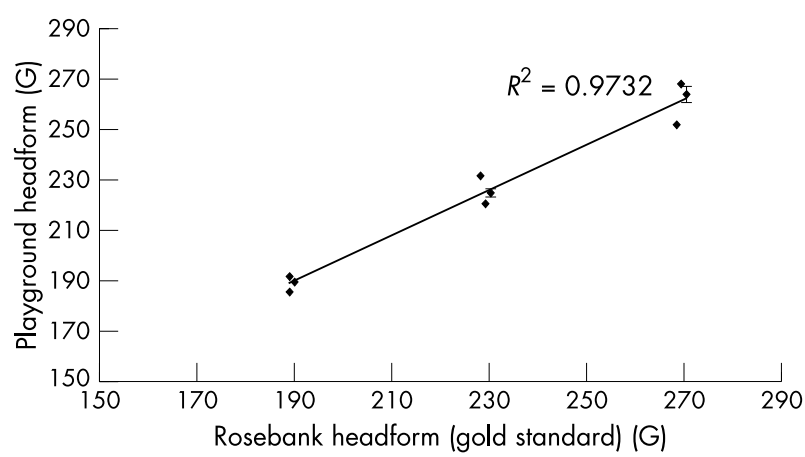

Figure 3 Results of playground headform validation tests conducted at $1 \mathrm{~m}, 1.25 \mathrm{~m}$, and $1.5 \mathrm{~m}$ drop heights. and met occupational health and safety regulations for the operators.

The rig was constructed to lift up to $50 \mathrm{~kg}$ to a maximum height of $3.5 \mathrm{~m}$ (upper range of equipment height from playground equipment audit). It could be disassembled into eight relatively flat sections for ease of transport.

Each impact test device (headform and arm load dummy) was attached to the rig via a quick release mechanism, selected for its ability to open with minimal extraneous perturbation of the test device sensors.

\section{Validation of instrumentation}

The validity of the headform output was tested under dynamic impact conditions at the Rosebank bicycle helmet laboratory in Hallam, Victoria. The playground headform was tested at heights of $1.0 \mathrm{~m}, 1.25 \mathrm{~m}$, and $1.5 \mathrm{~m}$ and compared to the output of the Rosebank headform (gold standard). The correlation between the deceleration output of the playground headform and the gold standard was 0.9732 (fig 3).

The dummy arm load cell was validated against standard instrumentation under static and dynamic laboratory conditions. Repeatability analysis (test-retest) of the load cell was performed.

Static validation tests were conducted using a Baldwin Universal Testing Machine, calibrated according to the National Association of Testing Authorities. ${ }^{25}$ A known direct compressive load was applied to the dummy arm and output from the load cell was measured three times for each incremental load.

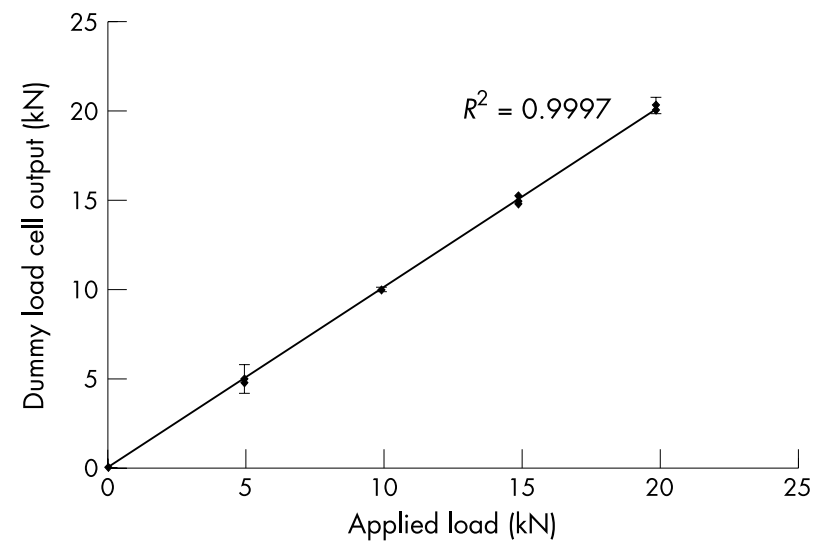

Figure 4 Response of dummy arm load cell to known applied loads under static conditions. 
Table 2 Static dummy strain gauge responses to known applied loads

\begin{tabular}{lllllll}
\hline $\begin{array}{l}\text { Applied load } \\
(\mathrm{kN})\end{array}$ & $\begin{array}{l}\text { Output 1 } \\
(\mathrm{kN})\end{array}$ & $\begin{array}{l}\text { Output 2 } \\
(\mathrm{kN})\end{array}$ & $\begin{array}{l}\text { Output 3 } \\
(\mathrm{kN})\end{array}$ & $\begin{array}{l}\text { Output } \\
\text { average }(\mathrm{kN})\end{array}$ & Error (\%) & $\begin{array}{l}\text { Repeatability } \\
(\%)\end{array}$ \\
\hline 0.00 & 0.09 & 0.12 & 0.09 & 0.10 & - & - \\
5.00 & 5.04 & 5.05 & 4.79 & 4.96 & -0.79 & 5.20 \\
10.00 & 10.05 & 10.00 & 9.92 & 9.99 & -0.10 & 1.30 \\
15.00 & 15.23 & 14.81 & 14.93 & 14.99 & -0.07 & 2.80 \\
20.00 & 20.26 & 20.01 & 20.01 & 20.09 & 0.45 & 1.25 \\
\hline
\end{tabular}

Correlation between output from the dummy load cell and the expected output for static loads up to $20 \mathrm{kN}$ was 0.9997 (fig 4). The error between observed and expected output ranged from $0.07-0.79 \%$, averaging less than $1 \%$ for each tested load. The repeatability of the three measures for each load ranged from $1.25 \%-5.20 \%$ (table 2 ).

Dynamic validation tests were conducted using an instrumented, calibrated Impulse Hammer as a pendulum (model 086C50, PCB Piezotronics, Buffalo, NY). Laboratory tests were conducted using a soft hammer interface to approximate the conditions of the playground surface at equivalent fall heights of $0.39 \mathrm{~m}, 0.5 \mathrm{~m}$, and $1.0 \mathrm{~m}$.

Dynamic loads were imparted to the dummy arm with expected load inputs measured directly from the hammer. Correlation was 0.9838 for expected load compared to arm load output up to $3.5 \mathrm{kN}$ (fig 5 ). The load cell was calibrated at regular intervals throughout the data collection period.

\section{Analysis methods}

Raw field test data were imported into Excel and arm load/time and deceleration/time traces were generated. From these traces, peak load, peak deceleration, and HIC were calculated. ${ }^{14}$ The highest reading (worst outcome) of three drop tests at each height was selected for further analysis. ${ }^{14}$

Once data collection is complete, analysis of the casecontrol study data will include univariate odds ratio calculations for each risk factor to identify potential effect modifiers and confounding factors, and multivariate analysis (logistic regression) to assess risk factors while controlling for confounders. The main variables of interest are equipment height, fall height, and surface impact characteristics.

\section{DISCUSSION}

The main strength of this method is the use of a multidisciplinary approach to identify the risk and protective factors for arm fracture in falls from playground equipment. The epidemiology/engineering interface enables risk factors to be reliably specified and their physical characteristics to be quantified.

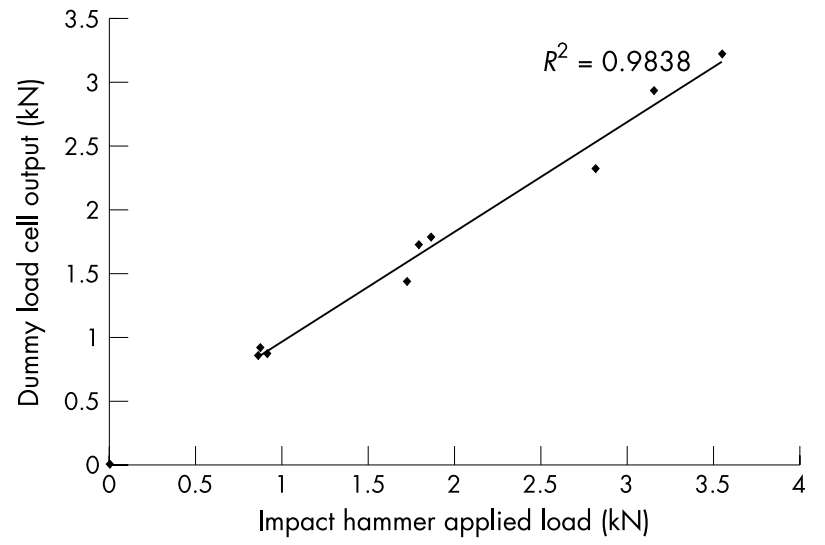

Figure 5 Response of dummy arm load cell under dynamic impact conditions.
Given the predominance of arm fractures resulting from falls from playground equipment, it was appropriate to develop an alternative measure to HIC more closely related to injury risk. Real world playground falls were recreated and peak deceleration and arm load quantified to determine the probability of arm fracture. The measures of fall height were based on the child's CoG and equipment height.

In selecting controls who fell and landed on their arm, all subjects were exposed to the playground height and surface risk factors of interest. There was a potential bias towards more serious falls (but not fractures) among controls, because children who were hurt were more likely to come to the teachers' attention. School staff were instructed to identify any children falling from playground equipment, not only children presenting with minor injury. Controls who presented to hospital were excluded. To assist with compliance, upon completion of the schools' commitment to the study, free playground surface material was provided to control schools.

Controls were from a randomised sample of schools. Cases who fell at control schools were included, allowing cases and controls to potentially fall on the same playground. The same playground did not necessarily equate to the same fall characteristics, which were considered unique for each fall event. Equipment height, fall height, and surface depth were widely represented in this study design. Since the laws of Newtonian physics are universal, the results are generalisable.

\section{Limitations}

The playground falls dummy, although modeled on the dimensions of the upper limb of a typical 6 year old child, did not conform to the exact biofidelity of the human arm. The dummy arm did not have a wrist or elbow joint and represented a relatively "stiff" surrogate. The stiffness of the dummy arm represented the worst case scenario of a fall onto an outstretched arm with joints locked and maximal loading on the long bones.

\section{Application}

These methods will identify risk and protective factors for arm fracture in children who fall from playground equipment, in particular the relationship between fall height and surface impact characteristics and risk of arm fracture. The arm load data compliments that obtained from the playground headform and adds to the limited body of knowledge about the biomechanics of child arm fractures.

The arm load data will underpin the development of a quantified arm fracture criterion. The future arm fracture criterion, when established as for HIC, will be applicable not only to the testing of playground and other surfaces, but also to the development of protective equipment, with potential application to sports and recreational injury prevention.

\section{Future potential studies}

This method could be further developed using computer modeling such as MADYMO to enable investigation of various fall heights and surface characteristics and to determine optimum playground conditions for injury prevention. A detailed review of case medical records could illuminate the relationship 


\section{Key points}

- Previous playground injury research has been limited in its ability to determine risk factors for arm fracture, despite their common and costly occurrence.

- A robust multidisciplinary method is presented to investigate and quantify physical risk factors for arm fracture in children who fall from playground equipment.

- The application of this method will determine critical equipment height and surface impact characteristics to inform arm fracture prevention and playground safety standards.

between fall impact biomechanics and the clinical severity of arm fracture to further inform playground standards. A study to determine the effective impact attenuation of organic surface materials over time is needed to guide maintenance schedules.

\section{ACKNOWLEDGEMENTS}

This work is funded by the National Health and Medical Research Council (project number 124414), the Victorian Health Promotion Foundation and the Department of Human Services. We thank Chris Powell and Roger Doulis, Monash University Department of Civil Engineering, for technical advice in developing the instrumentation Jim Nixon, University of Queensland Department of Paediatrics and Child Health, for loan of the playground headform; Len Koss, Monash University Department of Mechanical Engineering, for use of the Impact Hammer; Wendy Watson, Monash University Accident Research Centre, for coordinating the playground equipment audit; and Lesley Day, Monash University Accident Research Centre, for providing valuable comments on the methods.

\section{Authors' affiliations}

S Sherker, J Ozanne-Smith , G Rechnitzer, Accident Research Centre, Monash University, Melbourne, Australia

R Grzebieta, Department of Civil Engineering, Monash University, Melbourne, Australia

\section{REFERENCES}

1 Altmann A, Ashby K, Stathakis V. Childhood injuries from playground equipment. Report No 29. Melbourne: Monash University Accident Research Centre, 1996

2 Watson W, Ozanne-Smith J. The cost of injury to Victoria. Report No 124. Melbourne: Monash University Accident Research Centre, 1997.

3 Macarthur C, Hu X, Wesson DE, et al. Risk factors for severe injuries associated with fall from playground equipment. Accid Anal Prev 2000;32:377-82.
4 Chalmers DJ, Marshall SW, Langley JD, et al. Height and surfacing as risk factors for injury in falls from playground equipment: a case-control study. Inj Prev 1996;2:98-104.

5 Mowat DL, Wang F, Pickett W, et al. A case-control study of risk factors for playground injuries among children in Kingston and area. Inj Prev 1998;4:39-43

6 Laforest S, Robitaille, Lesage D, et al. Surface characteristics, equipment height, and the occurrence and severity of playground injuries. Inj Prev $2001 ; 7: 35-40$.

7 Mott A, Rolfe K, James R, et al. Safety of surfaces and equipment for children in playgrounds. Lancet 1997;349:1874-6.

8 Comité Européen de Normalisation. CEN 1177 : impact absorbing playground surfacing-safety requirements and test methods. Brussels: Comité Européen de Normalisation, 1997.

9 Sutcliffe R. The real case for synthetic surfacing? The Leisure Manager 1990: 13-14 (April).

10 Ball D, King K. Risk in the playground-the case for synthetic surfacing The Leisure Manager 1990 (March): 21-23.

11 Prasad P, Mertz HJ. The position of the United States delegation to the ISO working group 6 on the use of HIC in the automotive environment. Report No SAE paper No 851246 . Warrendale, PA: Society for Automotive Engineers, 1985.

12 Goldsmith W. Current controversies in the stipulation of head injury criteria. J Biomech 1981;14:883

13 American Society for Testing Material. ASTM F1292 standard specification for impact attenuation of surface systems under and around playground equipment. Philadelphia, PA: ASTM, 1991.

14 Standards Australia/New Zealand. AS/NZS 4422 playground surfacing-specifications, requirements and test methods. Homebush, NSW/Wellington: Standards Australia/New Zealand, 1996.

15 Winston FK, Schwarz DF, Baker SP. Biomechanical epidemiology: a new approach to injury control research. J Trauma 1996;40:820-4.

16 Rothman KJ, Greenland S. Precision and validity in epidemiological studies. Modern epidemiology. 2nd Ed. Philadelphia, PA Lippincott-Raven, 1998:115-34.

17 National Centre for Classification in Health. The international statistical classification of diseases and related health problems, 10th revision, Australian modification (ICD-10-AM). Sydney: NCCH, 1998.

18 Wacholder S, Silverman DT, McLaughlin JK, et al. Selection of controls in case-control studies. Am J Epidemiol 1992;135:1029-4 1

19 World Health Organization. Epilnfo-a wordprocessing, database and statistics program for public health. Geneva, Switzerland: WHO, 1996.

20 National Health and Medical Research Council. NHMRC-national statement on ethical conduct in research involving humans. Canberra: National Health and Medical Research Council, 1999.

21 Standards Australia. AS 1924-1: playground equipment for parks, schools and domestic use-general requirements. Homebush, NSW: Standards Australia, 1981.

22 Pheasant ST. Bodyspace: anthropometry, ergonomics and design. London: Taylor and Francis, 1986.

23 Snyder RG, Schneider LW, Owings CL, et al. Anthropometry of infants, children and youths to age 18 for product safety design. Report No UM-HSRI-77-17. Bethesda, MD: Consumer Product Safety Commission, 1977.

24 Norris B, Wilson JR. Childata: the handbook of child measurements and capabilities-data for design safety. Nottingham: Department of Trade and Industry, 1995

25 National Association of Testing Authorities (NATA). Available at: http://www.nata.asn.au/index.htm (accessed November 2002). 